\title{
Evaluating the Importance of Construction Activities for Sustainable Construction Practices in Building Projects in Nigeria
}

\author{
Peter Uchenna Okoye ${ }^{\mathrm{a}, *}$, Isaac Abiodun Odesola ${ }^{\mathrm{b}}$, Kevin Chuks Okolie ${ }^{\mathrm{a}}$ \\ ${ }^{a}$ Department of Building, Nnamdi Azikiwe University, Awka Nigeria \\ ${ }^{b}$ Department of Building, University of Uyo, Uyo Nigeria
}

Manuscript Received: March 27, 2020; Accepted October 6, 2020

\begin{abstract}
Construction activities inherently impact the environment, economy and the society positively and negatively. Optimisation of these activities for attainment of sustainable construction and development is very essential. Therefore, this study categorised and evaluated the construction activities necessary for sustainable construction practices in building project delivery. It employed the distribution of questionnaires to the consultants, professional, and building contractors, including the relevant employees of different Government ministries, departments and agencies responsible for the delivery of building projects across the five states of South East Nigeria. Through the application of the relative importance index (RII) analysis, the study revealed that out of the 55 construction activities identified and categorised based on the three key dimensions of sustainable construction, 35 were highlighted to have high important levels with RII value ranging between 0.804 and 0.990 ; and 20 were found to have high-medium important levels with RII value ranging between 0.602 and 0.794 . It further revealed that the five most important construction activities for sustainable construction were: use of naturally occurring building materials (0.990), use of recycled building materials (0.980), non- use of endangered materials (0.973), bioclimatic technology (0.966), and use of renewable resources (0.957) respectively. Interestingly, the result of the average RII of the three main sub-groups of construction activities showed that all the three main sub-groups of environmentally related construction activities $(\mathrm{RII}=0.841)$, economically related construction activities $(\mathrm{RII}=0.828)$ and socially related construction activities (RII $=0.808$ ) respectively were highly important to the attainment of sustainable construction practices. However, the study affirmed the indispensability of environmentally related activities among the tripod of sustainability in the effort towards achieving sustainable construction practices in the building industry, and highlighted the importance of salient activities that must not be ignored by building construction stakeholders in every building project. It therefore, recommended for a departure from the conventional construction practices and motives towards a hybrid construction practices that incorporates elements of sustainability.
\end{abstract}

Keywords: Building Projects; Construction Activities; Construction Practices; Sustainable Construction; Sustainable Development

\section{Introduction}

Sequel to the emergence of the sustainability agenda in the late 1980s, specific attention has been directed at putting up efforts that are conducted in a more thoughtful and responsible manner with future generations in mind [1]. This is reflected in the publication of the Brundtland's Report [1], and other global debates [2], locally, nationally and globally [3]. In recent years, the recognition of the importance of the construction industry for sustainability through sustainable development has gained widespread momentum. However, whilst a built environment is necessary for us to live, work and socialise, the construction of the facilities that allow us to do so have detrimental impacts on the environment [3].

The sustainable construction therefore, encapsulates the construction sector's response to sustainability [4].

* Corresponding author. Tel.: +2348036374662.

E-mail address: pu.okoye@unizik.edu.ng (P.U. Okoye)

https://doi.org/10.29187/jscmt.2020.47 
While this was borne out of concern for man's increasing consumption patterns vis-à-vis the limits of the earth's carrying capacity to sustain such patterns; there is no consensus as to what sustainable construction means, neither is there any universally accepted approach to it. However, schemes such as Agenda 21 for sustainable construction (A21-SC) set early directions for different countries to implement SC strategies and to drive research and development initiatives [5].

The responses to the sustainable construction agenda vary especially across different country contexts. The more developed countries of Europe, North America and some parts of Asia have been more proactive in recognising, developing and implementing sustainable construction agendas within their national contexts [6,7]. Multilateral organisations such as the International Council for Research and Innovation in Building and Construction (CIB) [5] and the United Nations Environment Programme (UNEP) in conjunction with few researchers [8-11] have attempted to extend the application of the sustainable development agenda to developing countries.

Unfortunately, Dania [4] observes that the recommendations from these efforts such as the Agenda 21 for sustainable construction in developing countries (A21-SCDC) have been largely prescriptive and not necessarily based on empirical evidence gathered from these contexts where these suggestions are meant to be implemented. Different studies [12-14] have attested to the poor sustainability nature of construction projects executed in most developing countries in recent times, and the Nigerian construction industry is no exception. This poor sustainability performance cut across all sectors where construction products are required in the country [15]. This situation is rather disheartening, considering the fact that construction projects are supposed to serve not just the present but also future generations. It then implies that our purpose towards construction practice is mainly output-oriented that brings about waste from all production processes [16] of construction. It further underscores the need to imbibe the concept of sustainable construction, so as to provide construction projects that will service generations to come. But considering the need to providing sustainable construction projects in a country where poor performance of construction work is prevalent, firstly identifying and evaluating various activities necessary for sustainable construction practices within the key dimensionality of sustainability in building projects delivery is very paramount. Therefore, this study categorises and evaluates the construction activities necessary for sustainable construction practices in Nigeria.

\section{Literature Review}

Sustainable construction practices are important and growing trend in the construction industry [17]. Lee, Ahn, Jeon and Suh [18] argue that construction stakeholders worldwide are transforming their organisational structures to implement sustainable construction practices that boost the "triple bottom line" of a building's ecological, social, and financial performance. However, different criteria have been used while discussing the dimensions of sustainable construction practices, depending on the context and the levels of decision making. But traditionally, sustainable construction has been described from perspective of three interrelated dimensions of sustainable development, namely economic, social and environmental pillars [19]. According to Schoormann, Behrens, Kolek, and Knackstedt [20], these three key dimensions of economic, ecological, and social factors are broadly and generally acknowledged by researchers over the years. They are also known as the Three Pillars of Sustainability.

Litman [21] agrees that sustainable construction includes a variety of environmental, social and economic issues. According to Pope, Annandale, and Morrison-Saunders [22], this model is used in local, regional, and national contexts of governance, business, and organisations. However, the similarity of the model is often criticised due to an unequal consideration given to them, that if one pillar breaks, it does not impact the entire unit [23]. But Purvis, Mao and Robinson [24] contend that despite the relative dearth of literature probing 'sustainability' and 'sustainable construction' conceptually, one conceptualisation, that of 'three pillars', environmental, economic, and social, has been generally widespread.

Consequently, since economic, social and environmental activities interact in so many ways, most experts now agree that sustainable construction requires balancing these various realms [21]. According to the UN Department of Economic and Social Affairs [25], several of this conceptual frameworks can be found in the existing literature describing the confluence of three constituent pillars: ecology, economy and equity. Enterprise Planning and Research Ltd (EPR) [26], agrees that these three key dimensions of sustainable development must be kept in balance in order to obtain the desired goals of sustainable development. Notwithstanding other forms of sustainability elsewhere in the literature, the triple bottom line remains the dominant model of sustainable development.

Meanwhile, parameters for measuring sustainable construction practice are not exhaustive, but however provide robust criteria for further development. Thus Leiringer [27] submits that sustainable construction practice does not necessarily involve additional responsibility but ethical implementation of good practices. In 
view of this, Enshassi, Al Ghoul and Alkilani [28] identified the most important sustainable factors that should be taken into consideration by engineers in the life cycle phases of construction project. Lee et al. [18] on the other hand, identified and categorised key sustainable practices and activities in a construction organisation both at project and company levels. Similarly, Rooshdi, Majid, Sahamir and Ismail [29] evaluated the importance of sustainable design and construction activities for green construction and found that the site management which is responsible by the contractors and authorities is the most important factor towards promoting the concept of sustainable development and achieving green highway. However, Mohamed and El-Meligy [30] contend that sustainability in construction practice is all about following suitable practices in terms of choosing materials, their sources and construction methodologies as well as design philosophy, so as to be able to improve performance, decrease the environmental burden of the project, minimise waste and be ecologically friendlier, take into consideration environmental, socio-economic and cultural values.

In spite of the growing concern, the general consensus from the global scene is that sustainability in construction practice has not been fully attained to improve construction performance substantially due to a number of barriers. Therefore, to be effective, the objectives must relate to the underpinning issues and be translated into realisable standards for performance, given the current technologies; practices and cultural factors [31].

\section{Methodology}

The study was a survey research that made use of structured questionnaire administered to three categories of building construction stakeholders (consultants/professionals, contractors and Government agents) in the SouthEast States of Nigeria. The questionnaire was designed to assess the importance of certain construction activities towards achieving sustainable construction practices in Nigeria. It was designed into two parts. Part 1 captured the respondents' demographic data; whereas Part 2 contained 55 variables extracted from the literature. They are categorised into three sub-groups (environmentally related, economically related and socially related), and measuring different construction activities and practices aimed at achieving sustainable construction. The respondents were asked to express their opinion on the importance of each activity towards achieving sustainable construction on a 5-point Likert Scale. Where $1=$ Least important, $2=$ Less important, $3=$ Important, $4=$ More important, 5 = Most important.

The population of this study constitute all building contractors obtained from the tenders' board of the five states of the South East Nigeria in the last five years without repetition. It also constitutes all the registered professionals in architecture, building, civil engineering, building services engineering, and quantity surveying and other relevant professionals in the built environment that are practicing in the study area and obtained from the register of the various professional associations in the states. The population also constituted all the staff of the ministries of work and housing and government agencies in charge of execution of building construction projects in the five states.

A total of 2244 contractors, professionals and government agents made up of the population for this study. But since it is practically impossible to obtain data from the entire population within the scope of a study, a suitable representative sample was obtained using the Cochran's iterative formula as shown in Equation 1 [32].

$$
\mathrm{n}_{0}=\frac{\mathrm{z}^{2} x(p)(q)}{e^{2}}
$$

Where:

$n_{0}=$ the sample size,

$z=$ the selected critical value of desired confidence level (standardised variable),

$p=$ the estimated proportion of an attribute that is present in the population (percentage picking a choice, expressed as a decimal), and $q=1-p$,

$e=$ the desired level of precision (confidence interval, expressed as a decimal).

To determine the sample size for a given level of accuracy for a large population whose degree of variability is not known, the maximum variability (the worst case percentage picking choice $(p)$ is assumed to be equal to $50 \%(p=0.5)$ as proposed by [33,34] and used by other researchers such as [35-37], is used and a 95\% confidence level is assumed with a significance level of $\alpha=0.05$; level of precision (e) of $\pm 5 \%$ and $\mathrm{z}=1.96$. These values were substituted into Equation 1 to estimate the minimum sample size for the study.

Therefore, 
$\mathrm{n}_{0}=\frac{1.96^{2} x(0.5)(0.5)}{(0.05)^{2}}=384.14 \approx 385$

Meanwhile, if the sample size $\left(\mathrm{n}_{0}\right)>5 \% \mathrm{~N}$ Cochran proposed a correction formula (see Equation 2) to calculate the final sample size, otherwise, $n_{0}$ becomes the satisfactory approximation to the sample size. In this case, the sample size (385) exceeds 5\% of the population size (2244). So, we applied Equation 2 to calculate the final sample size.

$$
\mathrm{n}=\frac{\mathrm{n}_{0}}{1+\left[n_{0}-\frac{1}{N}\right]}
$$

Where, $\mathrm{n}_{0}$ is the initial sample size derived from Equation 1 and $\mathrm{N}$ is the population size. Now, suppose we want to calculate the sample size for the population of our study where, population size is 2244 , the new sample size (n).

Substituting,

$$
\mathrm{n}=\frac{385}{1+\left[385-\frac{1}{2244}\right]}=329
$$

Questionnaires were directly distributed to the selected participants through a combination of stratified random and simple random sampling techniques due to the nature of the study and categories of respondents involved. Based on this, a total of 329 questionnaires were proportionately and randomly distributed to the respondents across the five states. Out of this number, 78 comprising 78 of professionals, 58 of contractors and 42 of government agents were retrieved and found adequate and suitable for analysis. This represented about $54.10 \%$ of the questionnaires distributed. The data generated from questionnaire survey were subjected to descriptive and quantitative analysis using tables and Relative Importance Index (RII).

Relative index analysis was selected in this study to rank the criteria according to their relative importance. Equation 3 is used to determine the relative importance index (RII).

$$
\text { Relative Importance Index }(\mathrm{RII})=\frac{\sum\left(f_{i} w_{i}\right)}{A x N}
$$

Where, $w_{i}=$ the weighting given to each variable by the respondents and ranges from 1 to $5 ; f_{i}=$ the number of response for each weight; $A=$ the highest weight (in this case, 5); and $N=$ the total number of sample.

Based on the ranking (R) of relative importance indices (RII), the weighted average of each of the construction activities and the collective average of the three sub-groups were determined. According to Akadiri [35], five important levels are transformed from RII values: high $(\mathrm{H})(0.8 \leq \mathrm{RII} \leq 1)$, high-medium $(\mathrm{H}-\mathrm{M})(0.6 \leq$ $\mathrm{RII} \leq 0.8)$, medium (M) $(0.4 \leq \mathrm{RII} \leq 0.6)$, medium-low (M-L) $(0.2 \leq \mathrm{RII} \leq 0.4)$ and low $(\mathrm{L})(0 \leq \mathrm{RII} \leq 0.2)$.

To ensure reliability of the result, the margin of error was computed at $95 \%$ confidence interval (C.I) within which the result would be acceptable. Margin of error (ME) is given as in Equation 4:

$\mathrm{ME}=$ critical value $\mathrm{x}$ standard error

Standard error $=$ standard deviation $/ \mathrm{V}_{\mathrm{n}}$

Where, $\mathrm{n}=$ the sample; The Alpha level $(\alpha): \alpha=1$-C.I $/ 100=0.05$

The critical probability $\left(\mathrm{p}^{*}\right): \mathrm{p}^{*}=1-\alpha / 2=1-0.05 / 2=0.975$

The degrees of freedom (df): $\mathrm{df}=\mathrm{n}-1=329-1=328$

Usually, the critical value is expressed as a t-statistic. Thus, the $t$ statistic has 328 degrees of freedom and a cumulative probability equal to 0.975 . From the t-Distribution, the critical value is found to be 1.96 .

Therefore, with finite population correction, the margin of error within which the result of this study would be 
reliable is $\pm 4.992 \%$ at the $95 \%$ confidence level. This is in line with Data Star (2008) [38] which suggested that an acceptable margin of error used by survey researchers falls between $4 \%$ and $8 \%$ at the $95 \%$ confidence level.

\section{Result and Discussion}

\subsection{Background information}

Table 1. Respondents background information

\begin{tabular}{|c|c|}
\hline Variable & Responses (\%) \\
\hline \multicolumn{2}{|l|}{ Categories of Respondents } \\
\hline Consultant/professional & 46.07 \\
\hline Contractor & 20.22 \\
\hline Government Agency & 33.71 \\
\hline \multicolumn{2}{|l|}{ Profession of Respondents } \\
\hline Building & 13.98 \\
\hline Architecture & 24.29 \\
\hline Engineering & 29.45 \\
\hline Quantity Surveying & 18.94 \\
\hline Management & 6.16 \\
\hline Others & 7.18 \\
\hline \multicolumn{2}{|l|}{ Job Position } \\
\hline Project/Construction Manager & 21.11 \\
\hline Engineer & 23.61 \\
\hline Supervisor & 31.67 \\
\hline Administrator & 5.43 \\
\hline Director & 3.08 \\
\hline Others & 15.10 \\
\hline \multicolumn{2}{|l|}{ Educational Level } \\
\hline Primary & 1.76 \\
\hline Secondary & 12.86 \\
\hline Higher institution & 58.29 \\
\hline Post graduate & 21.01 \\
\hline Others & 6.08 \\
\hline \multicolumn{2}{|l|}{ Working Experience } \\
\hline $0-5$ years & 8.65 \\
\hline 6-10 years & 17.01 \\
\hline 11-15 years & 42.23 \\
\hline $16-20$ years & 19.35 \\
\hline Above 20 years & 12.76 \\
\hline \multicolumn{2}{|c|}{ Type of Building Project Mostly Encountered } \\
\hline Residential & 19.35 \\
\hline Commercial/Office & 17.60 \\
\hline Industrial & 8.21 \\
\hline Institutional & 29.77 \\
\hline Others & 25.07 \\
\hline \multicolumn{2}{|l|}{ Type of Client } \\
\hline Private & 10.46 \\
\hline Public & 56.87 \\
\hline Quasi-public & 32.67 \\
\hline
\end{tabular}


Table 1 presents the general background information about the respondents. It showed that $46.07 \%$ of the respondent practice as either consultants or professionals in their different areas of profession, $20.22 \%$ were building contractors while $33.71 \%$ were employees of different government ministries, departments and agencies (MDAs) responsible for building project delivery the five states of South East Nigeria. Of these respondents, $13.98 \%$ belong to Building profession, 24.29\% Architecture profession, 29.45\% belong to Engineering, $18.94 \%$ belong to Quantity Surveying profession, 6.16\% to Management while 7.18\% belong to other professions. Out of these respondents, $85.92 \%$ indicated that they are registered members of their various professional organisations while $\%$ are not. Meanwhile, $21.11 \%$ of these respondents held the position of project/construction managers, $23.61 \%$ site engineers, $31.67 \%$ supervisors, $5.43 \%$ administrators (mainly from the government agencies), $3.08 \%$ were directors either in the construction organisations or in the government MDAs, and $15.10 \%$ of the respondents held other job positions not listed. This shows that majority of the respondents hold important positions in their various organisations.

In terms of educational level, $1.76 \%$ of the respondents were educated up to primary school level, $12.86 \%$ up to secondary school level, $58.29 \%$, more than half had their education up to high institution level, while $21.01 \%$ and $6.08 \%$ had post graduate certificate and other certificates such as trade certificates respectively. This shows that all the respondents are lettered and could give account of themselves in terms of responding to the questions in this study. Similarly, table 1 showed that the respondents have adequate working experience where only about $8.65 \%$ indicated that they had 5 years or lesser working experience. $17.01 \%$ of the respondents indicated that they had between 6-10 years working experience, $42.23 \%$ had between 11-15 years working experience, $19.35 \%$ had between 16-20 years working experience, while $12.76 \%$ indicated that they had above 20 years working experience,

When asked the type of building projects they encountered most often in the course of their practices, $19.35 \%$ indicated residential buildings, $17.60 \%$ went for commercial/office buildings, $8.21 \%$ indicated industrial building, while $29.77 \%$ and 25.07 indicated institutional and other type of buildings respectively. In a similar way, when asked the type of clients they mostly encounter, only a small percentage $(10.46 \%)$ of the respondents indicated private clients. Majority deal mostly with public (54.87\%) clients and quasi-public (32.67) clients.

\subsection{Analysis of importance of construction activities for sustainable construction practices}

Table 1. Ranking of different construction activities for sustainable construction practices

\begin{tabular}{|c|c|c|c|c|c|}
\hline Sub- & Variables & RII & Ranking by & Overall & Importance \\
\hline group & & & Category & Ranking & Level \\
\hline
\end{tabular}

Environmentally Related Construction Activities

2

4

5

6

7

Adaptation and use of cool roof concept

Lean construction concept

Retrofitting

Use of smart window technology

Rainwater harvesting technology and use

Reuse of grey water

Use of recycled building materials

Use of renewable resources spaces

Installation of indoor air quality sensors
Use of building information modelling (BIM) technology

Addition of trees, plants and gardens to the projects

Use of naturally occurring building materials

Use of prefabricated elements and components

Use of passive systems for cooling and ventilating interior

Exploitation and use of construction waste on construction sites

Vegetation preservation in construction site areas
0.841

0.826

0.889

0.931

$0.818 \quad 17$

$0.783 \quad 20$

$0.709 \quad 24$

$0.631 \quad 27$

$0.749 \quad 23$

$0.980 \quad 2$

$0.990 \quad 1$

$0.930 \quad 7$

$0.957 \quad 4$

$0.920 \quad 9$

$0.888 \quad 11$

$0.949 \quad 5$

$0.809 \quad 18$

1

H

H

$\mathrm{H}$

$\mathrm{H}$

$\mathrm{H}$

H-M

H-M

H-M

H-M

$\mathrm{H}$

$\mathrm{H}$

$\mathrm{H}$

$\mathrm{H}$

$\mathrm{H}$

H

H

H 


\begin{tabular}{|c|c|c|c|c|c|}
\hline 17 & Separation of waste skips on site & 0.669 & 25 & 49 & $\mathrm{H}-\mathrm{M}$ \\
\hline 18 & Reuse of demolition wastes & 0.874 & 12 & 24 & $\mathrm{H}$ \\
\hline 19 & Use of master switch to turn off all appliances & 0.645 & 26 & 50 & $\mathrm{H}-\mathrm{M}$ \\
\hline 20 & Use of alternative energy supplies (solar panels e.tc) & 0.822 & 16 & 32 & $\mathrm{H}$ \\
\hline 21 & Use of low or no VOC emitting paints \& adhesives & 0.772 & 21 & 41 & $\mathrm{H}-\mathrm{M}$ \\
\hline 22 & Use of bio-based products or materials & 0.849 & 14 & 28 & $\mathrm{H}$ \\
\hline 23 & Zero-carbon technology in new buildings & 0.926 & 8 & 14 & $\mathrm{H}$ \\
\hline 24 & Use of graphene coating technology & 0.756 & 22 & 43 & $\mathrm{H}-\mathrm{M}$ \\
\hline 25 & On-site energy generation technology & 0.867 & 13 & 25 & $\mathrm{H}$ \\
\hline 26 & Bioclimatic technology & 0.966 & 3 & 4 & $\mathrm{H}$ \\
\hline 27 & Habitat creation and restoration & 0.794 & 19 & 36 & $\mathrm{H}-\mathrm{M}$ \\
\hline \multicolumn{2}{|c|}{ Economically Related Construction Activities } & 0.828 & \multicolumn{2}{|r|}{2} & $\mathbf{H}$ \\
\hline 1 & Standardisation and modularisation & 0.943 & 2 & 9 & $\mathrm{H}$ \\
\hline 2 & Material and plant choice and selection techniques & 0.794 & 9 & 36 & $\mathrm{H}-\mathrm{M}$ \\
\hline 3 & Life cycle costing and whole life costing & 0.951 & 1 & 7 & $\mathrm{H}$ \\
\hline 4 & Integration of Net metering in design & 0.747 & 10 & 45 & $\mathrm{H}-\mathrm{M}$ \\
\hline 5 & Profitability improvement technology & 0.804 & 8 & 35 & $\mathrm{H}$ \\
\hline 6 & Just-In-Time production techniques & 0.835 & 7 & 29 & $\mathrm{H}$ \\
\hline 7 & Future adaptability and reuse & 0.935 & 4 & 11 & $\mathrm{H}$ \\
\hline 8 & Business opportunity creation & 0.637 & 11 & 52 & $\mathrm{H}-\mathrm{M}$ \\
\hline 9 & Business image enhancement strategy & 0.602 & 12 & 55 & $\mathrm{H}-\mathrm{M}$ \\
\hline 10 & Cost management strategy & 0.936 & 3 & 10 & $\mathrm{H}$ \\
\hline 11 & Economic regeneration & 0.883 & 6 & 23 & $\mathrm{H}$ \\
\hline 12 & Best-value procurement strategy & 0.901 & 5 & 18 & $\mathrm{H}$ \\
\hline \multicolumn{2}{|c|}{ Socially Related Construction Activities } & 0.808 & \multicolumn{2}{|r|}{3} & $\mathbf{H}$ \\
\hline 1 & Safety design integration & 0.918 & 4 & 17 & $\mathrm{H}$ \\
\hline 2 & Means of physical security & 0.782 & 11 & 40 & $\mathrm{H}-\mathrm{M}$ \\
\hline 3 & Accidents minimisation techniques & 0.857 & 8 & 27 & $\mathrm{H}$ \\
\hline 4 & Access to handicapped persons & 0.792 & 10 & 38 & $\mathrm{H}-\mathrm{M}$ \\
\hline 5 & Social utility function & 0.833 & 9 & 30 & $\mathrm{H}$ \\
\hline 6 & Quality of life improvement & 0.924 & 3 & 15 & $\mathrm{H}$ \\
\hline 7 & Employment opportunities creation & 0.746 & 13 & 46 & $\mathrm{H}-\mathrm{M}$ \\
\hline 8 & Integration of cultural heritage in building & 0.766 & 12 & 42 & $\mathrm{H}-\mathrm{M}$ \\
\hline 9 & Use of local materials and labour resources & 0.952 & 2 & 6 & $\mathrm{H}$ \\
\hline 10 & Attractive housing and public realm & 0.889 & 5 & 19 & $\mathrm{H}$ \\
\hline 11 & Non- use of endangered materials & 0.973 & 1 & 3 & $\mathrm{H}$ \\
\hline 12 & Sense of community attachment & 0.707 & 14 & 48 & $\mathrm{H}-\mathrm{M}$ \\
\hline 13 & Occupational health support system & 0.861 & 7 & 26 & $\mathrm{H}$ \\
\hline 14 & Opportunity of learning and self-development & 0.645 & 15 & 50 & $\mathrm{H}-\mathrm{M}$ \\
\hline 15 & Access to social infrastructure & 0.624 & 16 & 54 & $\mathrm{H}-\mathrm{M}$ \\
\hline 16 & Visual and thermal comfort & 0.884 & 6 & 22 & $\mathrm{H}$ \\
\hline
\end{tabular}

Table 2 shows the result of ranking of different construction activities for sustainable construction practices based on relative importance index. In overall, 55 variables were identified and categorised based on the three main dimensions of sustainable construction (environmental, economic and social). Based on these ranking results, 35 variables were highlighted to have high important levels in sustainable construction with a RII value ranging between 0.804 and 0.990 . Out of this number, 18 were environmentally related activities, 8 were 
economically related activities, whereas 9 were socially related activities. The five most important activities for sustainable construction across all dimension include: use of naturally occurring building materials (0.990), use of recycled building materials (0.980), non- use of endangered materials (0.973), bioclimatic technology $(0.966)$ and use of renewable resources $(0.957)$ respectively.

However, the three most important environmentally related activities for sustainable construction include: use of naturally occurring building materials (0.990), use of recycled building materials (0.980), and bioclimatic technology (0.966) respectively. the three most important economically related activities for sustainable construction include; life cycle costing and whole life costing (0.951), standardisation and modularisation (0.943). and cost management strategy (0.936); while that of socially related activities include; non- use of endangered materials (0.973), use of local materials and labour resources (0.952), and quality of life improvement $(0.924)$ respectively.

The result of Table 2 further shows that all the five most important construction activities but one (non- use of endangered materials) are environmentally related activities. This underscores the importance of maintaining a natural and balanced environment for sustainability of our construction practices. It also accentuates the unequal consideration being given to the tripod of sustainable construction [23], despite their interdependent. This position is further substantiated by the average relative importance indices of the three sub-groups of sustainable construction practices where the average relative importance index of environmentally related construction activities is 0.841 , that economic activities is 0.828 and socially related construction activities is 0.808 respectively. Averagely, all the three sub-groups were found to be highly important to sustainable construction with environmentally related construction activities being the most important sub-group for sustainable construction practices.

Interestingly, all the identified 55 construction activities for sustainable construction equally fall within the high $(\mathrm{H})$ or high-medium (H-M) importance levels. Whereas the six overall lowest ranking activities include; use of master switch to turn off all appliances (0.645), opportunity of learning and self-development (0.645), business opportunity creation (0.637), addition of trees, plants and gardens to the projects $(0.631)$, access to social infrastructure (0.624), and business image enhancement strategy $(0.602)$; the lowest environmentally related ranked activity was addition of trees, plants and gardens to the projects $(0.631)$. The lowest economically and socially related ranked activities for sustainable construction practices were business image enhancement strategy (0.602) and access to social infrastructure (0.624) respectively. This is an indication of the importance of sustainable construction practices in every building project. The overall result of this study implies that sustainable construction practices cannot be achieved in building construction industry without considering activities relating to the tripod of sustainability which include environment, economy and society.

\section{Conclusion}

Although sustainable construction practices are very important to the survival of the building industry and mankind as a whole, certain activities related to these practices are vital in the course of building practice. This study has categorised and evaluated the importance of construction activities for sustainable construction practices in building projects. Through literature review, a total of 55 construction activities were identified and categorised into three main sub-groups known as the tripod of sustainability. Based on the relative importance index computation, the study has found that all the activities fall within high (35) and high-medium (20) importance level. This implies that all the identified construction activities relating to environmental, economic and social sustainability are very important to the attainment of sustainable construction practices in the building industry. The study further highlighted the significant important of environmental sustainability which is crucial to a balanced environment where man can live and operate.

Irrefutably, the study highlighted the importance of salient activities that must be considered in every building project. The study also revealed certain construction activities which are of utmost important to the attainment of sustainable construction practices. This implies that construction stakeholders such as the consultants, professionals, contractors and government agencies in charge of construction projects have to pay particular attention to these activities in the course of discharging the professional and legal duties. Diligent and methodical consideration of these activities would lead to sustainability in the building construction industry, and to a greater extent sustainable development. Therefore, the result of this study would guide the consultants, professionals, contractors and government agencies in carrying out their obligations especially during project monitoring and supervision. This to say that the result of this study has a lot of policy implications on the part of the government, professional associations, individual professionals and contractors.

On the strength of this study, there is need for a departure from the conventional construction practices and motives towards a hybrid construction practices that incorporates elements of sustainability. It also calls for the attention of government agencies and consultants/professionals to construction activities that would lead to 
sustainable construction practices.

\section{References}

1. World Commission on Environment and Development (WCED), Our Common Future, Oxford, Oxford University Press, 1987.

2. C. du Plessis, Action for Sustainability: Preparing an African Plan for Sustainable Building and Construction, Building Research and Information, 33(5), 405-415, 2005.

3. M. Brennan and A. Cotgrave, Development of a Measure to Assess Attitudes Towards Sustainable Development in the Built Environment: A Pilot, In: Smith, S.D and Ahiaga-Dagbui, D.D (Eds), Proceedings of the $29^{\text {th }}$ Annual ARCOM Conference, 2-4 September 2013, Reading, UK, Association of Researchers in Construction Management, 1265-1273, 2013.

4. A.A. Dania, Sustainable Construction at the Firm Level: Case Studies from Nigeria, PhD Dissertation, 2016.

5. International Council for Research and Innovation in Building and Construction (CIB), Agenda 21 on Sustainable Construction in Developing Countries, Rotterdam, CIB Report Publication 237, 1999.

6. T. Lawrence, C.A. Balaras and J.K. Means, A Comparison of How Sustainability and Green Building Standards are being Adopted into Building Construction Codes within the United States and the EU, Proceedings of the International Conference on Sustainable Built Environment, SBE 16 - Strategies- Stakeholders- Success Factors, Hamburg, Germany, 8-11 March, 2016, $42-51$.

7. Y. Zhang, H. Wang, W. Gao, F. Wang, N. Zhou, D.M. Kammen, et al., A Survey of the Status and Challenges of Green Building Development in Various Countries, Sustainability, 11, 5385, 2019.

8. N.Z. Abidin, Sustainable Construction Practices in Malaysia, In: I. Dincer, A. Hepbasli, A. Midilli, and T.H. Karakoc (Eds) Springer Science+Business Media, 2010

9. C. du Plessis, Sustainability and Sustainable Construction: The African Context, Building Research and Information, 29(5), 374380,2001

10. R.M. Reffat, Sustainable Construction in Developing Countries, Proceedings of First Architectural International Conference, Cairo University, Egypt, 2004

11. F. Shafii, Z.A. Ali and M.Z. Othman, Achieving Sustainable Construction in the Developing Countries of Southeast Asia, Proceedings of the 6th Asia-Pacific Structural Engineering and Construction Conference (APSEC 2006), Kuala Lumpur, Malaysia, 2006.

12. Y.M. Al-Salah and H.M. Talab, The Integration of Sustainability within Value Management Practices: A Study of Experienced Value Managers in the GCC countries, Project Management Journal, 41(2), 50-59, 2010.

13. A.A. Alabi, Comparative Study of Environmental Sustainability in Building Construction in Nigeria and Malaysia, Journal of Emerging Trends in Economics and Management Sciences, 3(6), 951-961, 2012.

14. J.M. Hussin, I.A. Rahman and A.H. Memon, The Way Forward in Sustainable Construction: Issues and Challenges, International Journal of Advances in Applied Sciences (IJAAS), 2(1), 15-24, 2013.

15. D Aghimien, C Aigbavboa, A. Oke and C. Musenga, Barriers to Sustainable Construction Practices in the Zambian Construction Industry, Proceedings of the International Conference on Industrial Engineering and Operations Management, 26 -27 July 2018 , Paris, France. 2383-2392.

16. D. Lee, Overcoming the Culture of Waste, MIT Sloane Experts, MIT Sloan School of Management, 2017.

17. K. Keeler, C.M. Clevenger and R. Atadero, Framework for Sustainability Challenges within the Building Industry, Proceedings of the Associated Schools of Construction 49th Annual International Conference, 10-13 April 3013, San Luis Obispo, California.

18. K.H. Lee, Y.H. Ahn, M. Jeon and M.J. Suh, Organisational Strategies to Support Sustainability in the Construction Company, In the World SB14, 28-30th October 2014, Barcelona, Spain.

19. D. Loucks and J. Gladwell, Sustainability Criteria for Water Resource Systems, Cambridge: Cambridge University Press, 1999.

20. T. Schoormann, D. Behrens, E. Kolek and R. Knackstedt, Sustainability in Business Models - A Literature-Review-Based DesignScience-Oriented Research Agenda, Twenty-Fourth European Conference on Information Systems (ECIS), İstanbul, Turkey, 2016.

21. T. Litman, Well Measured: Developing Indicators for Sustainable and Liveable Transport Planning, Victoria Transport Policy Institute, 2019.

22. J. Pope, D. Annandale and A. Morrison- Saunders, Conceptualising Sustainability Assessment, Environmental Impact Assessment Review, 24(6), 595-616, 2004.

23. N.K. Dawe and K.L. Ryan, The Faulty Thee Legged Stool-Model of Sustainable Development, Conversation Biology, 1458-1460, 2003.

24. B. Purvis, Y. Mao and D. Robinson, Three Pillars of Sustainability: In Search of Conceptual Origins, Sustainability Science, 14, 681-695, 2019

25. United Nations Department of Economic and Social Affairs, Division for Sustainable Development, Prototype Global Sustainable Development Report, New York: United Nations, 2014.

26. EPR, Sustainability, Enterprise Planning and Research Ltd, 2009.

27. R. Leiringer, Some Observations on 'Doing' and 'Writing' Quality Research., In: S. Laryea and R. Leiringer (Eds.), Proceedings of the 6th West Africa Built Environment Research (WABER) Conference, 10-12 August 2015, Accra, Ghana, 7-48. 
28. A. Enshassi, H. Al Ghoul and S. Alkilani, Exploring Sustainable Factors during Construction Projects' Life Cycle Phases, Revista Ingeniería de Construcción, 33(1), 51-68, 2018.

29. R.R.R.M. Rooshdi, M.Z.A. Majid, S.R. Sahamir and N.A.A. Ismail, Relative Importance Index of Sustainable Design and Construction Activities Criteria for Green Highway, Chemical Engineering Transactions, 63, 151-156, 2018.

30. A.S.Y. Mohamed and D.A.A. El-Meligy, Sustainability Tomorrow in Construction Materials and Technologies, IACSIT International Journal of Engineering and Technology, 5(1), 25-31, 2013.

31. A.M.M. Liu, W.S.W. Lau and R.F. Fellows, The Contributions of Environmental Management Systems Towards Project Outcome: Case Studies in Hong Kong, Architectural Engineering and Design Management, 8, 160-169, 2012.

32. R. Czaja and J. Blair, Designing Surveys: A Guide to Decisions and Procedures, Thousand Oaks, London, Pine Forge Press, 1996.

33. B.B. Hazarika, Factors affecting interest in mathematics among upper primary school students-A study on the basis of the students of Guwahati, PhD Dissertation, Guwahati University, 2013.

34. O.P. Akadiri, Development of a Multi-Criteria Approach for the Selection of Sustainable Materials for Building Projects, PhD Thesis, University of Wolverhampton, Wolverhampton, UK, 2011.

35. A. Alkharmany, Project Management: The Effect of Saudi National Culture on the Attitudes of Key Stakeholders towards Delay in Construction Projects in Saudi Arabia, PhD Dissertation, University of Brighton, 2017.

36. B.O. Ganiyu, Strategy to Enhance Sustainability in Affordable Housing Construction in South Africa, Doctor of Technology Dissertation, the Cape Peninsula University of Technology, South Africa, 2016.

37. W.G. Cochran, Sampling Techniques, 3rd Ed., John Wiley \& Sons Inc. New York, 1977.

38. Data Star, What Every Researcher Should Know About Statistical Significance, 2008. 